\title{
Health related quality of life of HIV/AIDS patients on highly active anti-retroviral therapy at a university referral hospital in Ethiopia
}

Abdrrahman Shemsu Surur ${ }^{1 *}$, Fitsum Sebsibe Teni ${ }^{2}$, Wondwessen Wale ${ }^{1}$, Yihenew Ayalew ${ }^{1}$ and Betel Tesfaye ${ }^{1}$

\begin{abstract}
Background: Highly active antiretroviral therapy improves the longevity of patients living with HIV/AIDS. We conducted the study in order to assess health related quality of life of HIV/AIDS patients and the association of socio-demographic and disease related variables with health related quality of life.

Methods: Health facility based cross-sectional study among 400 HIV/AIDS patients taking highly active anti-retroviral therapy from Gondar University referral hospital was conducted. A pre-tested semi-structured questionnaire, which was adopted from World Health Organization Quality of life brief instrument, was used. The data were then analyzed using SPSS version 20 software for Windows.

Results: The majority of the respondents reported to to have a good physical health (15.55). The World Health Organization clinical stage was found to be significantly associated with all the domains of health related quality of life. The current acute illness condition of the respondents, however, did not show significant association with any of the domains of health related quality of life.

Conclusions: The six domains of health related quality of life were found to be moderate. The physical health and spirituality of the patients were relatively higher than their social relationship. Sex, age, educational status, residence and marital status showed significant association with at least one domain of health related quality of life.
\end{abstract}

Keywords: Health related quality of life, Patients living with HIV/AIDS, HAART, WHOQOL-HIV BREF

\section{Background}

Since the beginning of the epidemic, about 39 million people have died of HIV/AIDS. Globally, 35.0 million people were living with HIV at the end of 2013. SubSaharan Africa remains most severely affected with nearly 1 in every 20 adults living with HIV [1]. Moreover, the alarming increase of HIV/AIDS, inability to afford highly active anti-retroviral therapy (HAART), disability, stigma, loss of productivity due to illness, and chronic nature of the disease has made HIV/ AIDS one

\footnotetext{
* Correspondence: lowerurexpect@gmail.com

1Department of Pharmaceutical Chemistry, School of Pharmacy, College of Medicine and Health Sciences, University of Gondar, Gondar, Ethiopia

Full list of author information is available at the end of the article
}

of the most important public health problems in subSaharan Africa countries.

People living with HIV/AIDS (PLWHA) show different symptoms which may involve flu-like symptoms like fever or rash occurring for a month or two after infection. Chronic diarrhea, rapid weight loss and other opportunistic infections and infection related cancers start appearing after many years [2]. In terms of mental health, in comparison with the general population PLWHA may be more likely to develop to develop mental disorders like depression or anxiety and major depression is the commonest psychiatric problem occurring associated to the disease $[3,4]$.

HIV/AIDS has also been associated in a complex way with impoverished housing conditions. The challenges of slums in urban areas like basic services, inadequate 
water, sanitation, overcrowding and others are worsened by the impact of HIV/AIDS. Problems like inadequate water and sanitation increase the disease burden [5]. Reports have also indicated that homelessness and unstable housing have been associated with greater HIV risk, to poor health outcomes and early death among PLWHA [6].

HAART has shifted the perception of HIV/AIDS from a fatal to a chronic and potentially manageable disease. The use of HAART has become the cornerstone of the clinical intervention to prevent transmission and slow progression of HIV infection in individuals living with HIV/AIDS [7]. However the medications are associated with adverse effects which may contribute to decreased adherence to regimens. These included bone density events, dyslipidemia, GI effects, hepatic effects, diabetes mellitus/ insulin resistance, Stevens-Johnsons Syndrome, renal effects, rash and lipodystrophy which are attributed to most of the HAART medication groups. Protease inhibitors are associated with bleeding events and cholestiasis, and nucleoside reverse transcriptase inhibitors (NRTIs) are linked to bone marrow suppression and lactic acidosis [8]. The spectrum of adverse effects related to HAART in developing countries may differ from that in developed countries because of the high prevalence of conditions such as anemia, malnutrition, and tuberculosis and frequent initial presentation with advanced HIV disease [9].

A review on HAART adherence and interventions reported that HIV stigma and discrimination by friends and family were associated to non adherence. Fear that friends and family might find out HIV status was also one of the reasons for skipping doses. Depression, similar symptoms and anxiety were reported to be associated strongly with non adherence [10]. Another review listed a number of reasons which negatively affect adherence in both developed and developing countries. These included fear of disclosure, forgetfulness, lack of understanding of treatment benefits, complicated regimens as well as being away from medications while medication access and financial problems were more common in the developing countries [11].

On the contrary, lower levels of psychological distress, higher levels of life satisfaction, and higher self-efficacy for adopting medication compliance behaviors were associated with increased adherence. The belief in the medications ability to improve quality of life has also been associated with better adherence [10]. As longevity of PLWHA improves as a result of HAART, the most important question for health professionals and policy makers will be how to maximize quality of life (QoL) [12].

According to the World Health Organization (WHO), "health is a state of complete physical, mental, and social well-being and not merely the absence of disease or infirmity". This is particularly true for PLWHA because of the chronic and debilitating nature of the illness and the stigma and discrimination [13].

The term QoL has been used to describe the overall sense of well being with respect to happiness and general level of satisfaction with life. It incorporates various domains including health, housing, jobs, schools, the neighborhood, culture, values and spirituality which make it complex to measure [14]. QoL has also been used to describe the extent to which human needs are met or the level of perception of satisfaction or dissatisfaction of individuals or groups in various life domains. It is summarized as an indicator of the extent of fulfillment of objective human needs in relation to personal or group perceptions of subjective well being [15].

Health-related quality of life (HQoL) is a multidimensional component of the patient reported outcome which involves patients evaluation of themselves based on perception of a disease and/or its treatments [16]. HQoL encompasses the aspects of QoL which influence physical or mental health. These include physical and mental health perceptions and various conditions which can affect them. These are health risks and conditions, functional status, social support, and socioeconomic status [14].

Many different instruments have been developed to describe and quantify HQoL. These include HIV-specific instruments such as the medical outcomes study-HIV [17], the HIV overview of problems evaluation system (HOPES) [18] and the WHO Quality of Life instrument module (WHOQOL) for international assessment of HIV/AIDS [19]. The WHOQOL-HIV instrument provides a promising means for quality of life assessment for PLWHA in diverse cultural settings [20].

The WHOQOL-HIV instrument focus on six major domains, referred to as Physical, Psychological, Level of independence, Social, Environmental and Spiritual. Those domains of HQoL are varied in terms of the socio-demographic characteristics and disease related variables. "Socio-demographic characteristics, including age, gender, education, income employment status, and disease related variables such as disease state, opportunistic infection and CD4 count, have been found to be strongly associated with HQoL of PLWHA" [21].

In the effort to document and assess HQoL of PLWHA various studies have been conducted globally and locally using the WHO Quality of Life of HIV specific instrument brief (WHOQOL-HIV BREF). Among these were findings from studies in Bangladesh and Vietnam which reported low to moderate levels of means scores of QoL in the six domains assessed. The relatively highest scores in the cited studies were for the domains of spirituality and environmental health from the Bangladesh and Vietnam studies respectively $[22,23]$. 
Other studies from Africa also reported on the level of QoL of PLWHA on HAART using WHOQOL BREF including findings from Nigeria where occupation, income, education and discrimination were found to be associated with QoL scores for many of the domains. A finding from Zambia reported a high proportion of patients with good or very good levels of quality of life [24, 25].

In Ethiopia few studies have been conducted which assessed QoL among PLWHA focusing on the change in HQoL of patients after initiation of HAART, predictors HQoL of QoL and gender differences in QoL [26-29]. Another study from the northwestern town of Bahir Dar in Ethiopia also reported on QoL of PLWHA which was found to be low in almost all of the domains including general (1.85), physical (2.55), psychological (2.66), social (6.4) and mental (6.4) from a maximum of $8,24,32,16$ and 24 respectively [30].

Despite the conduct of numerous studies on HQoL of PLWHA across the world and the availability of measuring instruments, such studies are limited in Ethiopia [31-33]. In addition, assessing HQoL of PLWHA on HAART is important to indicate the status of patients on the therapy. This study, therefore, assessed the perceived HQoL of PLWHA in Gondar University Referral Hospital (GURH) using WHOQOL-HIV BREF. The present study also assessed the individual domain scores and the presence of relationship between those domains and, socio-demographic characteristics and disease variables. It is hoped the result will identify the HQoL domains with poor result and the factors responsible, so that health professionals and policy makers who are involved in the care of PLWHA get informed of the kind of problems that need to be tackled.

\section{Methods}

\section{Study setting and design}

A health facility based cross-sectional study was conducted at GURH, which is located in the northwestern Ethiopian town of Gondar. The institution is a referral and teaching hospital with a catchment population of more than 5 million. GURH is a 400 beds hospital with a range of specialties including pediatrics, surgery, gynecology, internal medicine, HIV care and various others (GURH Statistics and Information Office: Annual Report on Health Services and Employees, Gondar, Ethiopia 2013, unpublished).

\section{Sampling}

The sample size of the participants to be included in this study was calculated using a single proportion formula. In calculating the sample size, a $\mathrm{z}$ value of 1.96 as the degree of accuracy at $95 \%$ confidence interval, proportion of PLWHA with QOL level of better than average was assumed to be $50 \%$ and the margin of error was considered 0.05 . Based on this the sample size was calculated to be 385 and with a $5 \%$ addition for possible nonresponse the final sample size was 403 .

The study population was any PLWHA above 18 years of age and who came to GURH HAART pharmacy for taking HAART during the study period. However, HIV/ AIDS patients with incomplete medical chart, mental illness or patients not willing to participate in this study were excluded. Incomplete medical chart refers to the absence of CD4 count or WHO clinical stage of the patients. Psychiatric patients who were not in a position to appropriately respond for the items provided were classified as mentally ill and were excluded.

The study was conducted during the period of April 2014 to May 2014. The total number of active HAART users at GURH was 5394. Considering the 22 weekdays within a study period and a relatively uniform flow of patients across each day, every 14th patient was included in the study. The first client was selected daily through drawing a number from 1 up to 14 and continuing with every 14th number until the daily sample limit was reached. Accordingly, the daily sample limit was 19 patients for 7 days and 18 patients for 15 days.

\section{Data collection instrument and process}

A semi-structured questionnaire containing mostly closed ended and a number of open ended questions was developed by adopting WHOQOL-HIV BREF. The instrument was translated into Amharic language and disease related variables including CD-4 count and WHO clinical stage were added. Hence, it contained socio-demographic, clinical and the six domains of health-related quality of life. The Amharic questionnaire was translated back to English to ensure the translated version gives the proper meaning. The revised Amharic questionnaire was pre-tested using 40 patients and the final version was produced.

Data concerning CD-4 count and the WHO clinical stage of the patients were extracted from their medication record. The data were collected by three final year undergraduate pharmacy students through intervieweradministered questionnaire. The data collection was made between 8:00 AM and 5:00 PM at the HAART pharmacy of GURH for a duration of one month from April 05 to May 04, 2014.

The semi-structured questionnaire consisted of 31 five point Likert scale items, which are grouped into six domains of HQoL; physical health, psychological well-being, level of independence, social relation, environmental health and spiritual health.

The Physical domain describes 4 facets: pain and discomfort, energy and fatigue, sleep and rest and symptoms related to HIV. The Psychological domain describes 5 facets: positive feelings, concentration, 
self-esteem, bodily image and appearance and negative feelings. The Level of independence domain describes 4 facets: mobility, activities of daily living, dependence on medication and treatment and work capacity. The Social relationships domain describes 4 facets: personal relationships, social support, sexual activity, and social inclusion. The Environment domain describes 8 facets: physical safety and security, home environment, financial resources, health and social care: accessibility and quality, opportunities for acquiring new information and skills, participation in and opportunities for recreation activities, physical environment, transport. The Spiritual domain describes 4 facets: personal beliefs, forgiveness and blame, concerns about the future, death and dying [34].

Individual items are rated on a 5 point Likert scale where 1 indicates low, negative perceptions and 5 indicates high, positive perceptions. Facet scores are the mean of the four items in each facet. Domain scores were computed first by adding the facet in the respective domain, then dividing it by the number of facets in that domain, and eventually by multiplying it with 4 . The domain scores were multiplied by 4 so as to be directly comparable with the scores used in WHO quality of life-100 (WHOQOL-100). Accordingly, the score ranged from 4 (worst possible HQoL) to 20 (best possible $\mathrm{HQoL}$ ) [35].

\section{Data entry and analysis}

The Data collected were entered into and analyzed using Statistical Package for Social Sciences (SPSS) version 20.0 software for Windows. The domains' mean scores were calculated using WHO user manual on how to score and code WHOQOL-HIV instruments. Domain scores were scaled in a positive direction where higher scores denote higher HQoL. Some items like dependence on medication and death pain were scaled in a negative direction, meaning that for these facets higher scores do not denote higher HQoL. These items were reversed so that high scores reflect better HQoL. Hence, the formula 6-x was used [35]. Cronbach's alpha coefficient was calculated to determine the internal consistency of the instrument. Independent $t$ test was employed to assess the difference in HQoL domain between sex, age, place of residence, current acute illness and $\mathrm{CD}-4$ count. On the other hand, one-way analysis of variance (ANOVA) was used to check the difference among educational status, marital status and WHO clinical stage with regard to domains of HQoL. In doing so the different analysis of $95 \% \mathrm{CI}$ and $P$-value of less or equal to 0.05 was taken as cutoff value for statistical significance.

\section{Results}

Socio-demographic characteristics

During the one-month interview period, 468 patients were approached for the participation. 65 of the patients were not willing to participate and 3 questionnaires were discard for the lack of complete medical chart. Of the total of 400 participants, more than half the respondents were female $(54.8 \%)$. Most of the respondents were above the age of $30(60.8 \%)$ and resided in urban areas (73\%). The percentage of the respondents who were married and had finished their secondary education was $42.8 \%$ and $35.5 \%$ respectively. A clinical stage one $(66.8 \%)$ was predominant and the majority of the participants $(55.5 \%)$ had a current CD-4 count less than 500 cells $/ \mathrm{mm}^{3}$ [Table 1].

Table 1 The socio-demographic characteristics of the respondents, GURH 2014

\begin{tabular}{|c|c|}
\hline Variables & Frequency (\%) \\
\hline \multicolumn{2}{|l|}{ Sex } \\
\hline Male & $181(45.3)$ \\
\hline Female & $219(54.7)$ \\
\hline \multicolumn{2}{|l|}{ Age } \\
\hline$<30$ & $157(39.5)$ \\
\hline$\geq 30$ & $243(60.8)$ \\
\hline \multicolumn{2}{|l|}{ Current CD-4 count (cell/mm³) } \\
\hline$<500$ & $222(55.5)$ \\
\hline$\geq 500$ & $178(44.5)$ \\
\hline \multicolumn{2}{|l|}{ Marital status } \\
\hline Single & $108(27.0)$ \\
\hline Married & $171(42.8)$ \\
\hline Divorced & $70(17.5)$ \\
\hline Widowed & $51(12.8)$ \\
\hline \multicolumn{2}{|l|}{ Residence } \\
\hline Urban & $292(73.0)$ \\
\hline Rural & $108(27.0)$ \\
\hline \multicolumn{2}{|l|}{ Educational status } \\
\hline Illiterate & $100(25.0)$ \\
\hline Primary & $95(23.7)$ \\
\hline Secondary & $142(35.5)$ \\
\hline Higher education & $63(15.8)$ \\
\hline \multicolumn{2}{|l|}{ WHO clinical stage } \\
\hline Stage 1 (Asymptomatic) & $267(66.8)$ \\
\hline Stage 2 (Mild symptoms) & $105(26.3)$ \\
\hline Stage 3 (Advanced symptoms) & $25(6.3)$ \\
\hline Stage 4 (Severe symptoms) & $3(0.8)$ \\
\hline
\end{tabular}


Table 2 The mean scores of domains of HQoL and overall perception of HQoL, GURH 2014

\begin{tabular}{ll}
\hline Domains & Mean $( \pm \mathrm{SD})$ \\
\hline Physical health & $15.55(3.04)$ \\
Psychological health & $13.93(2.80)$ \\
Level of independence & $15.27(3.25)$ \\
Social relationship & $12.11(2.85)$ \\
Environment health & $12.78(2.33)$ \\
Spirituality health & $15.47(3.47)$ \\
Overall perception of HQoL & $12.57(2.96)$ \\
\hline
\end{tabular}

\section{The overall HQoL}

The mean score of HQoL was the highest for the physical domain (15.55), followed by the spirituality domain (15.47), the level of independence domain (15.27), the psychological domain (13.92), the environment domain (12.78) and the social relationship domain (12.11) [Table 2].

Cronbach's alpha was used to determine the internal consistency of the instrument as well as its domains. The Cronbach's alpha coefficient of physical domain (0.82), spiritual domain (0.89), level of independence domain (0.88), physical domain (0.81), environmental domain (0.85) and social domain (0.79) were adequate.

Patients were asked to rate their perception to overall quality of life, using a scale ranged from very poor (score of 1 ) to very good (score of 5). Half of patients (50\%) rated their overall perceived HQoL as neither good nor poor, by giving a score value of 3 . A significantly higher number of patients $(32.75 \%)$ rated their overall perceived HQoL as good compared to those who rated their overall perceived HQoL as poor (14.5\%) or very poor (2.75\%). Accordingly, the overall perceived quality of life by PLWHA is $62.55 \%$.

\section{Difference in HQoL among respondents}

The association between the mean scores of HQoL domains and the socio-demographic characteristics and disease related variables was examined. Based on the independent samples $t$ test performed on some sociodemographic characteristics and disease related variables, the sex and age of participants were significantly associated with the psychological health. Patients who live in urban areas showed higher level of independence compared to those who live in rural areas. However, the current illness condition and the level of CD-4 of the respondents do not show significant association with any of the six domains of HQoL [Table 3].

In one-way ANOVA performed on portions of sociodemographic and disease related variables, the WHO clinical stage showed significantly association with all of the six domains of HQoL. The educational status of the respondents was found to be strongly associated with the social relationship and environmental health. In addition, marital status was significantly associated with the environmental health of the respondents [Table 4].

\section{Discussion}

The study assessed the HQoL of PLWHA who came to receive HAART from the HAART pharmacy of GURH.

Table 3 Test of significance of variation (Independent sample $t$ test) in HQoL by socio-demographic characteristics and disease variables, GURH 2014

\begin{tabular}{|c|c|c|c|c|c|c|c|}
\hline Variables & & Physical health & $\begin{array}{l}\text { Psychological } \\
\text { health }\end{array}$ & $\begin{array}{l}\text { Level of } \\
\text { independence }\end{array}$ & Social relation & $\begin{array}{l}\text { Environmental } \\
\text { health }\end{array}$ & Spirituality \\
\hline \multirow[t]{3}{*}{ Sex } & Male & 15.392 & 13.829 & 14.966 & 12.237 & 12.897 & 15.663 \\
\hline & Female & 15.675 & 14.020 & 15.516 & 12.004 & 12.678 & 15.310 \\
\hline & T-test & -0.928 & $-0.676^{* *}$ & -1.686 & 0.814 & 0.940 & $1.011^{* *}$ \\
\hline \multirow[t]{3}{*}{ Age } & $<30$ & 15.636 & 13.966 & 15.452 & 12.191 & 13.130 & 15.369 \\
\hline & $\geq 30$ & 15.489 & 13.912 & 15.148 & 12.057 & 12.549 & 15.535 \\
\hline & T-test & 0.472 & $0.189^{* *}$ & 0.914 & 0.457 & 2.455 & -0.465 \\
\hline \multirow[t]{3}{*}{ Residence } & Urban & 15.657 & 14.134 & 15.411 & 12.119 & 12.804 & 15.575 \\
\hline & Rural & 15.250 & 13.392 & 14.879 & 12.083 & 12.703 & 15.185 \\
\hline & T-test & 1.190 & -0.676 & $1.454^{*}$ & 0.114 & 0.385 & 0.998 \\
\hline \multirow{3}{*}{$\begin{array}{l}\text { Current acute } \\
\text { illness }\end{array}$} & Yes & 13.9380 & 12.6822 & 13.7752 & 11.2171 & 12.1473 & 14.0465 \\
\hline & No & 16.3134 & 14.5403 & 15.9851 & 12.5410 & 13.1119 & 16.1381 \\
\hline & T-test & -7.7940 & -6.4950 & -6.6750 & -4.4420 & -3.9520 & -5.8500 \\
\hline \multirow[t]{3}{*}{ CD-4 count } & $<500$ & 15.2973 & 13.7838 & 14.9414 & 11.9189 & 12.4910 & 15.4279 \\
\hline & $\geq 500$ & 15.8596 & 14.1213 & 15.6742 & 12.3483 & 13.1348 & 15.5225 \\
\hline & T-test & -1.8420 & -1.1990 & -2.2520 & -1.501 & -2.7740 & -0.2700 \\
\hline
\end{tabular}

$P^{*}<0.05, P^{* *}<0.01$ 
Table 4 Test of significance of variation (one-way ANOVA test) in HQoL by socio-demographic characteristics and disease variables, GURH 2014

\begin{tabular}{|c|c|c|c|c|c|c|c|}
\hline Variables & & Physical health & $\begin{array}{l}\text { Psychological } \\
\text { health }\end{array}$ & $\begin{array}{l}\text { Level of } \\
\text { independence }\end{array}$ & Social relation & $\begin{array}{l}\text { Environmental } \\
\text { health }\end{array}$ & Spirituality \\
\hline \multirow[t]{5}{*}{ Educational status } & Illiterate & 15.040 & 13.504 & 14.8900 & 11.3100 & 12.0600 & 15.4800 \\
\hline & Primary & 15.600 & 14.012 & 15.1789 & 12.2211 & 12.3737 & 15.4947 \\
\hline & Secondary & 15.704 & 14.090 & 15.5915 & 12.4155 & 13.1268 & 15.3662 \\
\hline & Higher education & 15.920 & 14.1460 & 15.2698 & 12.5238 & 13.7381 & 15.6208 \\
\hline & F-test & 1.382 & 1.0790 & 0.9430 & $3.7430^{* *}$ & $9.3200^{* *}$ & 0.1000 \\
\hline \multirow[t]{5}{*}{ Marital status } & Single & 15.4537 & 13.9037 & 15.1204 & 12.4259 & 13.1435 & 15.3333 \\
\hline & Married & 15.5263 & 13.8012 & 15.2164 & 11.8947 & 12.4064 & 15.5848 \\
\hline & Divorced & 15.7143 & 14.1829 & 15.4857 & 12.0857 & 12.8786 & 15.4000 \\
\hline & Widowed & 15.5882 & 14.1020 & 15.4510 & 12.1961 & 13.1078 & 15.4706 \\
\hline & F-test & 0.1090 & 0.3760 & 0.2460 & 0.7850 & $2.764^{*}$ & 0.1270 \\
\hline \multirow[t]{5}{*}{ WHO clinical stage } & Stage-1 & 15.9401 & 14.2772 & 15.8090 & 12.4607 & 13.1610 & 15.9288 \\
\hline & Stage-2 & 14.7619 & 13.2800 & 14.0381 & 11.5048 & 12.0429 & 14.5333 \\
\hline & Stage-3 & 14.6400 & 13.2480 & 14.8000 & 10.8800 & 11.9800 & 14.5200 \\
\hline & Stage-4 & 15.6667 & 12.0000 & 14.0000 & 12.3333 & 11.0000 & 15.3333 \\
\hline & F-test & $4.6850^{* *}$ & $4.3300^{* *}$ & $8.2280^{* *}$ & $4.6140^{* *}$ & $7.8570^{* *}$ & $4.8650^{* *}$ \\
\hline
\end{tabular}

In this study, HIV/AIDS was prevalent in patients with secondary educational status (35.5\%). Only $15.8 \%$ of the respondents have attended higher education studies, a status which might increase the awareness and method of prevention against HIV/AIDS. A study in Brazil also showed that 8 years of education is associated with better HQoL [36].

Some studies have documented low performance for women in some aspects of HQoL [37] while in some other studies had shown the opposite [22]. In this study, female respondents showed a significantly higher psychological health than men. This can be attributed to many factors including, but not limited to, increased fertility desire of women following the use of HAART [7].

Urban residents showed higher values in all domains of HQoL than PLWHA in rural areas. A relatively better financial status, infrastructures and increased support for patients in urban areas might be some of the contributing factors for this difference. Among the domains urban residents recorded a statistically significant higher score in terms of level of independence which could be attributed to the relatively less physically demanding activities in urban areas compared to farming in rural areas.

All the domains of HQoL showed a higher mean scores than a study in Bangladesh, the only exception being the social relationship domain. The mean score of the social relation domain (12.11) was lower than the Bangladesh study (12.98). The reason behind this may be due to the different study design used or a difference in socio-demographic characteristics or the presence a relatively more stigma and discrimination in Ethiopia which had been and continues to be a serious problem associated to the disease [22, 38]. The domain mean scores of this study and a study in Bangladesh were much higher than those reported in the studies in Bahir Dar and Iran [22, 26, 37]. The results from the Bahir dar study, however, cannot be compared directely to this study as different data collection tools were used. The perceived overall quality of life (12.57) found in this study can be considered as moderate using a median of HQoL mean scores (a value of 10) as a cut-off point.

The mean scores of social relationship and environmental health were lower than any other aspects of HQoL. A study conducted in Nigeria [39] also reported that PLWHA had a lower quality in the social relationships and environment domain. Those results may be related to discrimination as well as poor living conditions in their physical environment. The psychological health (13.93) was found to be lower than physical health, level of independence and spirituality. This result is an indicative of signifying the need to combine HAART with psychological interventions.

In this study, WHO clinical stage showed a significant association with all domains of HQoL. A similar relation is reported in the Bangladesh study, which found a significant association of WHO clinical stage with the physical health, level of independence, perception of HQoL and perception of overall health [22]. The higher WHO clinical stages may be associated to limited day-to-day activities, which may eventually results in poor HQoL. 
A higher CD-4 count was reported to be associated with better HQoL, especially with regard to physical domain [7]. In this study, however, CD-4 count didn't not show a statistically significant association with any of the domains of HQoL. Moreover, a similar no association was reported in the study conducted in Bahir Dar [30].

In this study, current acute illness was found to bear no significant relation with all domains of HQoL. However, Socio-demographic characteristics like age, residence, educational status and marital status showed a significant association with one or more domains of HQoL. The study from Bangladesh also reported a significant association of age and place of residence with one or more of domains of HQoL. The Bahir dar and the Iran studies, however, found no significant association between educational status or marital status and any domains of HQoL [22, 30, 37].

This study has managed to add to the scarce literature in the area of quality of life of HIV/AIDS patients in Ethiopia and can be helpful in showing points of intervention to stakeholders to intervene toward improving the life of PLWHA.

\section{Limitations}

The study had some limitations as it included only patient taking HAART. Inclusion of HIV patients who did not start HAART would have given a more comprehensive result. Researches with a different study design, including qualitative methods, can overcome this limitation.

\section{Conclusions}

The six domains of HQoL were found to be moderate. The physical health and spirituality of the patients were relatively higher than their social relationship. Sex, age, educational status, residence and marital status were significantly associated with at least one domain of HQoL. Moreover, WHO clinical stage was strongly associated with all HQoL domains.

Strategies to improve psychological supports and environmental health, and strengthening social relations seems relatively more demanding than other domains of HQoL. Primary health care support can be used to improve the psychological and environmental health of PLWHA. In this aspect health care providers can use the findings to focus their interventions to address the social aspects of the problems of their patients in addition to the clinical aspects. Social sensitization to avoid stigma and discrimination can improve those domains of HQoL since it may help to create a sense of safe living conditions or help PLWHA to receive a necessary support from their friends.

\section{Abbreviations}

ANOVA: Analysis of variance; Cl: Confidence interval; GURH: Gondar University Referral Hospital; HAART: Highly active anti-retroviral therapy; HOPES: HIV overview of problems evaluation system; HQoL: Health related quality of life; PLWHA: People Living With HIV/AIDS; SPSS: Statistical Packages for Social Sciences; WHO: World Health Organization; WHOQOL BREF: World Health Organization quality of life of HIV specific instrument brief

\section{Acknowledgements}

The authors acknowledge the support of the School of Pharmacy, College of Medicine and Health Sciences, University of Gondar, in facilitating the data collection process. The authors also extend their appreciation to the pharmacist working in the HAART pharmacy of GURH and HIV/AIDS patients who participated in the study.

\section{Funding}

No funding was received in the conduct of this study.

\section{Availability of data and materials}

The datasets supporting the conclusions of this article are included within the article.

\section{Authors' contributions}

ASS: adopted data collection instrument, supervised data collection; ASS and FST conceived the study; ASS and WW: involved in the development of the proposal acquisition; WW, YA and BT: conducted data acquisition; ASS, FST, WW, YA and BT: performed analysis and interpretation of data; ASS and FST: drafted the manuscript and revised it, and ASS, FST, WW, YA and BT: approved its submission. All authors read and approved the final manuscript.

\section{Ethics approval and consent to participate}

The study was approved by School of Pharmacy, College of Medicine and Heath Sciences, University of Gondar. Based on this a letter of support was written to the hospital. During data collection each study participant was asked for verbal consent to participate in the study after provision of all the necessary information about the nature of the study. The data collection instrument in the study did not use patient identifiers and after collection the data were kept strictly confidential and were used only for the purpose of the study.

\section{Consent for publication}

Not applicable

\section{Competing interests}

The authors declare that they have no competing interests.

\section{Publisher's Note}

Springer Nature remains neutral with regard to jurisdictional claims in published maps and institutional affiliations.

\section{Author details \\ ${ }^{1}$ Department of Pharmaceutical Chemistry, School of Pharmacy, College of Medicine and Health Sciences, University of Gondar, Gondar, Ethiopia. ${ }^{2}$ Department of Pharmaceutics and Social Pharmacy, School of Pharmacy, College of Health Sciences, Addis Ababa University, Addis Ababa, Ethiopia.}

Received: 9 September 2015 Accepted: 8 November 2017

Published online: 15 November 2017

References

1. Global Health Observatory data, WHO. http://www.who.int/gho/hiv/en/ accessed 1 Aug 2015.

2. National Institutes of Health (NIH). HIV Overview. HIV/AIDS: The Basics. 2015. https://aidsinfo.nih.gov/understanding-hiv-aids/fact-sheets/19/45/hiv-aidsthe-basics. Accessed 04 August 2016.

3. Arseniou S, Arvaniti A, Samakouri MHIV. Infection and depression. Psychiatry Clin Neurosci. 2014:68:96-109.

4. National Institutes of Health (NIH). Transforming the understanding and treatment of mental illnesses. 2016. https://www.nimh.nih.gov/health/topics/ hiv-aids/index.shtml. Accessed 04 August 2016.

5. Rooftops Canada Abri international/ Interagency Coalition on AIDS and Development. HIV, AIDS and housing issues. March 2010. Rooftops Canada 
Abri international/ Interagency Coalition on AIDS and Development. http://www.icad-cisd.com/pdf/Housing_Fact_Sheet_Final_EN.pdf. Accessed 05 August 2016.

6. The National AIDS Housing Coalition HIV/AIDS Housing: Breaking the Link between Homelessness and HIV. The NAHC housing and HIV/AIDS research summit series. http://federalaidspolicy.org/wp-content/uploads/2014/03/Breakingthe-Link-Between-Homelessness-and-HIV-9-12.pdf. Acessed 06 August 2016

7. Oguntibeju OO. QoL of people living with HIV and AIDS and HAART. HIV/AIDS (auck). 2012:4:117-24.

8. Panel on Antiretroviral Guidelines for Adults and Adolescents. Adverse effects of antiretroviral agents. In: Guidelines for the use of antiretroviral agents in HIV-1-infected adults and adolescents. Department of Health and Human Services; 2016. http://www.aidsinfo.nih.gov/ContentFiles/Adultand AdolescentGL.pdf. Accessed 05 August 2016.

9. Subbaraman R, Chaguturu SK, Mayer KH, Flanigan TP, Kumarasamy N. HIV/ AIDS: adverse effects of highly active antiretroviral therapy in developing countries. CID. 2007:45:1093-101.

10. Reisner SL, Mimiaga MJ, Skeer M, Perkovich B, Johnson CV, Safren SAA. Review of HIV antiretroviral adherence and intervention studies among HIV-infected youth. Top HIV Med. 2009;17(1):14-25.

11. Mills EJ, Nachega JB, Bangsberg DR, Singh S, Rachlis B, Wu P, et al. Adherence to HAART: a systematic review of developed and developing nation patient reported barriers and facilitators. PLoS Med. 2006;3(11):e438. doi:10.1371/ journal.pmed.0030438.

12. Wu AW. Quality Of life assessment comes of age in the era of highly active antiretroviral therapy. AIDS. 2000;14(10):1449-51.

13. Clayson DJ, Wild DJ, Quarteman P, Duprtan-Lommon I, Kubin M, Coons SJA. Comparative review of HQoL measures for use in HIV/AIDS clinical trials. PharmacoEconomics. 2006;24(8):751-65.

14. U.S. Department Of health and human services. Measuring healthy days: population assessment of health-related quality of life. U.S. department of health and human services. Centers for Disease Control and Prevention national, Center for Chronic Disease Prevention and Health Promotion, division of adult and Community Dent Health November 2000. https:/www.cdc.gov/ hrqol/pdfs/mhd.pdf. Accessed 04 August 2016.

15. Costanza R, Fisher B, Ali S, Beer C, Bond L, Boumans R, et al. Quality of life: an approach integrating opportunities, human needs, and subjective well-being. Ecol Econ. 2007:61:267-76.

16. European Network for Health Technology Assessment (Eunethta). Guideline: endpoints used for relative effectiveness assessment of pharmaceuticals, health-related quality of life and utility measures. European network for health technology assessment. February 2013. http://www.eunethta.eu/ sites/5026.fedimbo.belgium.be/files/Endpoints\%20used\%20for\%20Relative \%20Effectiveness\%20Assessment\%20Health\%20related\%20quality\%20 of\%20 life\%20and\%20utility\%20measures_Amended\%20JA1\%20Guideline_Final \%20Nov\%202015.pdf. Accessed 05 August 2016.

17. Smith MY, Feldman J, Kelly P, Dehovitz JA, Chirgwin K, Minkoff H. HQoL of HIV-infected women: evidence for the reliability, validity and responsiveness of the medical outcomes study short-form 20. Qual Life Res. 1996;5(1):47-55.

18. O'Leary JF, Ganz PA, AW W, Coscarelli A, Petersen L. Towards a better understanding of HQoL: a comparison of the medical outcomes study HIV health survey (MOS-HIV) and HOPES. J Acquir Immune Defic Syndr Hum Retrovirol. 1998;17:433-44.

19. The WHOQOL-HIV Group. Initial steps to developing the World Health Organization's quality of life instrument (WHOQOL) module for international assessment of HIV/AIDS. AIDS Care. 2003;15:347-57.

20. Peltzer K, Phaswana-Mafuya N. HQoL in a sample of HIV-infected south Africans. Afr J AIDS Res. 2008;7:209-18.

21. Basavaraj KH, Navya MA, Rashmi R. QoL in HIV/AIDS. Indian J Sexual Transm Dis. 2010;31(2):75-80.

22. Imam MH, Karim MR, Ferdous C, Akhter S. HQoL among the people living with HIV. Bangladesh Med Res Counc Bull. 2011;37:1-6.

23. Tran BX. QoL outcomes of antiretroviral treatment for HIV/AIDS patients in Vietnam. PLoS One. 2012;7(7):e41062. doi:10.1371/journal.pone.0041062.

24. Mofolorunsho KC, Nwanko EO, Mofolorunsho TB. Socio-economic factors influencing QoL of PLWHA in Kogi, Nigeria. Nature and. Science. 2013;11:33-9.

25. Mweemba P, Zeller R, Ludwick R, Gosnell D. Quality of life of Zambians with HIV/AIDS. Med J Zambia. 2009;36(4):143-50.

26. Wubshet M, Berhane Y, Worku A, Kebede Y. Perception and predictors of quality of life among HIV patients attending HAART clinics in northwest Ethiopia: a prospective longitudinal study. Ethiop Med J. 2014;52(3):119-27.
27. Mekuria LA, Sprangers MA, Prins JM, Yalew AW, Niewkerk PT. Health-related quality of life of HIV-infected adults receiving combination antiretroviral therapy in Addis Ababa. AIDS Care. 2015;27(8):934-45.

28. Tesfay A, Gebremariam A, Gerbaba M, Abrha H. Gender differences in health related quality of life among people living with HIV on Highly active antiretroviral therapy in Mekelle Town, Northern Ethiopia. Biomed Res Int 2015;516369. doi: 10.1155/2015/516369.

29. Deribew A, Deribe K, Reda AA, Tesfaye M, Hailmichael Y, Maja T, Colebunders R. Change in quality of life: a follow up study among patients with HIV infection with and without TB in Ethiopia. BMC Public Health. 2013;13:408.

30. Alemu A, Yenealem A, Feleke A, Meseret S. HQoL assessment and associated factors among people on HAART at Felege Hiwot referral hospital. J AIDS Clin Res. 2013;5(1):1-5.

31. Pedram R, Kaveh H, Behtash S, Gholamreza D, Mehrnaz R, Mahboube H, Koosha P, Parastoo K, Mahsa F, Seyd A, Minoo M, Willi M. QoL among persons with HIV/AIDS in Iran. Reliability and validity of an international instrument and associated factors. AIDS Res Treat. 2012, Article ID 849406, 6 pages; doi:10.1155/2012/849406.

32. Kabbash IA, El-Gueneidy M, Sharaf AY, Hassan NM. And al-Nawawy. Needs assessment and coping strategies of person infected with HIV in Egypt. East Mediterr Health J. 2008;14(6):1308-20.

33. Nglazi MD, West SJ, Dave JA, Levitt NS, Lambert EV. Quality of life in individuals living with HIV/AIDS attending a public sector HAART service in cape town, South Africa. BMC Public Health. 2014;14:676. http://www.biomedcentral.com/ $1471-2458 / 14 / 676$

34. WHO. Development of the World Health Organization WHOQOL-BREF quality of life assessment. The WHOQOL group. Psychol Med. 1998;28:551-8.

35. WHO: Scoring and coding for the WHOQOL-HIV instruments. 2002. Department of mental health and substance dependence: 1-13.

36. Campos LN, César CC, Guimarães MC. Quality of life among HIV-infected patients in Brazil after initiation of treatment. Clin Sci. 2009;64(9):867-75.

37. Nojomi M, Anbary K, Ranjbar M. Health related quality of life in patients with HIV/AIDS. Arch Iran Med. 2008;11(6):608-12

38. Lifson AR, Demissie W, Tadesse A, Ketema K, May R, Yakob B, et al. HIV/AIDS stigma-associated attitudes in a rural Ethiopian community: characteristics, correlation with HIV knowledge and other factors, and implications for community intervention. BMC International Health and Human Rights. 2012;12:6.

39. Fatiregun AA, Mofolorunsho CK, Osagbemi KG. QoL of PLWHA in Kogi state, Nigeria. Benin. J Postgrad Med. 2009;11:21-7.

\section{Submit your next manuscript to BioMed Central and we will help you at every step:}

- We accept pre-submission inquiries

- Our selector tool helps you to find the most relevant journal

- We provide round the clock customer support

- Convenient online submission

- Thorough peer review

- Inclusion in PubMed and all major indexing services

- Maximum visibility for your research

Submit your manuscript at www.biomedcentral.com/submit
) Biomed Central 